\title{
Bentuk Perpaduan Nyanyian Himne Dan Nyanyian Rohani Kontemporer Dalam Ibadah Di Gereja Kemah Injil Indonesia Jemaat Talitakumi Makassar
}

\author{
Yohana Marturia Manilani
}

\begin{abstract}
Abstrak
Tujuan penulisan skripsi adalah mengetahui bentuk perpaduan seperti apakah yang dipakai untuk memadukan nyanyian himne dan nyanyian rohani kontemporer dalam ibadah di Gereja Kemah Injil Indonesia Jemaaat Talitakumi Makassar. Adapun hasil penelitian dapat disimpulkan sebagai berikut: Pertama, Para pendiri gereja kebanyakan mereka yang berlatar belakang Calvinis, yang lebih menerima pemakain nyanyian himne dengan iringan pianao tunggal, dibandingkan dengan pemakain musik kontemporer (fullband). Kedua, karena kelompok ini memiliki paradigma bahwa nyanyian kontemporer merupakan nyanyian yang memiliki makna theologi yang kurang dalam, jika dibandingkan dengan nyanyian himne, yang menurut mereka merupakan nyanyian yang agung dan juga memiliki makna teologi dalam. Ada juga kendala dari kelompok yang kurang menerima pemakaian himne yaitu: Pertama, adanya pemahaman bahwa nyanyian himne (NKI) merupakan nyanyian yang susah di mengerti jika dilihat dari syairnya yang syairnya yang bersifat puitis. Kedua, nyanyian himne merupakan nyanyian orang tua, sehingga lebih banyak digandrungi oleh orang tua. Metode apa yang efektif untuk digunakan dalam memadukan nyanyian himne dan nyanyian kontenporer dalam pelaksanaan ibadah adalah Pertama, menyanyikan nyanyian himne dengan sajian musik kontemporer. Bentuk perpaduan ini merupakan sala satu bentuk yang menurut penulis lebih cocok untuk digunakan dalam ibadah di Gereja Kemah Inijil Indonesia Talitakumi Makassar, sebagai sala satu cara untuk mengubah paradigma dari kelompok jemaat yang kurang menerima penggunaan nyanyian dan musik kontemporer dalam ibadah. Kedua, menggunakan kedua jenis nyanyian yaitu nyanyian himne dan nyanyian rohani kontemporer dalam liturgi ibadah.
\end{abstract}

Kata-kata Kunci: Bentuk, Perpaduan, Nyanyian, Himne, Kontemporer, Ibadah. 


\section{Pendahuluan}

\section{Latar Belakang Masalah}

Nyanyian adalah ungkapan hati seseorang yang diekspresikan melalui syair dan nada, yang merupakan hal penting bagi kehidupan, baik itu kehidupan secara individu maupun universal. Allah sendiri yang menciptakan nyanyian dengan tujuan agar melalui nyanyian umat ciptaannya dapat memuji dan menyembah-Nya sebagai Allah pencipta yang berkuasa.

Melalui nyanyian juga para tokoh agama kita yang terdahulu telah memuliakan Tuhan dan menyembah-Nya. Contohnya raja Daud, di mana ia menyanyikan pujian dan mazmur bagi Allah atas pertolongan bagi orang Israel (Mazmur 66:1, 2). Setiap kemenangan yang telah dialami oleh bangsa Israel selalu disertai dengan ungkapan syukur oleh Daud di mana ia memuji dan mengagungkan keperkasaan-Nya.

Nyanyian pujian itu terus berlangsung hingga pada saat ini di mana generasi kita sekarang dalam setiap gereja dan persekutuan tentunya menjadikan nyanyian sebagai salah satu bagian yang terpenting dalam ibadah untuk menyembah Tuhan. Dari zaman ke zaman nyanyian telah menjadi hal yang universal. Salah satu contohnya dapat dilihat pada penggunaan nyanyian di dalam pelaksanaan ibadah, di mana dalam suatu ibadah apabila tidak terdapat nyanyian maka ibadah itu bisa dikatakan tidak hidup sebab nyanyian merupakan sarana yang menciptakan suasana yang hidup dalam ibadah serta kesatuan, yang membawa orang dalam sikap menyembah.

Dalam nyanyian juga terdapat unsur yang sangat penting yaitu melalui nyanyian orang dapat mengungkapkan rasa syukur kepada Tuhan serta mengingatkan kembali betapa besar dan dahsyat kasih yang Allah berikan. Hal ini dapat dilihat dari peristiwa yang dialami oleh umat Israel yang dipimpin oleh Nabi Musa untuk menyanyikan puji-pujian yang menyatakan kedahsyatan Allah ketika mereka berhasil menyeberangi laut Teberau dan mengalami pembebasan (Keluaran 15:1-21). ${ }^{1}$

Selain nyanyian merupakan sarana yang digunakan untuk nyatakan ungkapan syukur, nyanyian juga dapat digunakan sebagai senjata yang digunakan untuk meraih kemenangan-kemanangan dalam peperangan rohani. ${ }^{2}$

Dari pernyataan ini dilihat bahwa nyanyian memegang peranan yang penting di mana nyanyian dapat membawa orang masuk kepada pengenalan akan Allah yang dapat mengubah kehidupan orang menuju pada jalan yang benar.

${ }^{1}$ Sadhu Sundar Selvaraj, Seni Menyembah Menjadi Penyembah yang Dicari Tuhan (Jakarta: Nabiri Gabrie, 1996), 41-44.

${ }^{2}$ Bob Sorge, Mengungkapkan Segi Pujian dan Penyembahan (Yogyakarta: ANDI 1991), 45. 
"Nyanyian gereja adalah nyanyian persekutuan, dan apabila dilihat dari istilah dalam himnologi dapat dikatakan bahwa nyanyian orang banyak (community singing)". " Nyanyian yang ditempatkan Tuhan dalam hati setiap orang, akan mulai mengalir keluar dan ini terjadi secara spontan, di mana katakata dari nyanyian itu bukan keluar dari pikiran melainkan dari hati, sehingga ketika nyanyian itu dinyanyikan, maka orang akan mengalami kelepasan di dalam roh dan memperoleh kemerdekaan yang baru, dan apabila nyanyian itu dinyanyikan dengan Roh dan penuh pengertian kepada Tuhan, maka penyanyipenyanyi yang di surga juga akan menyatakan syukurnya melalui pujian. ${ }^{4}$ Maksud dari pernyataan ini adalah nyanyian yang dinyanyikan bukanlah dilihat dari keindahan syair atau kata-kata dari nyanyian tersebut melainkan dari pengekspresiannya, ${ }^{5}$ sebagai salah satu wujud bahwa seseorang memiliki sikap hati yang memuji Tuhan dan yang mau bersekutu dengan-Nya.

Dalam setiap gereja tentu saja terdapat nyanyian-nyanyian yang ditetapkan untuk mendukung jalannya ibadah baik itu nyanyian himne ataupun nyanyian kontemporer yang telah disusun dalam liturgi yang merupakan tempat di mana kita menyanyikan akan sebuah pengharapan dan masa depan serta sekaligus menjadi sarana di mana umat dapat terhanyut oleh visi mengenai kerajaan yang sedang datang. ${ }^{6}$ Setiap pujian yang telah diatur dapat dipakai untuk memuji dan memuliakan nama Tuhan. Hendaklah nyanyian yang dinyanyikan oleh setiap orang memiliki satu tujuan yaitu untuk memuji dan menyembah kepada Kristus dalam roh dan kebenaran bukan dengan daging. ${ }^{7}$

Salah seorang tokoh musik gerejawi, Manawe yang adalah seorang teolog Perjanjian Lama dari Indonesia juga memberikan perhatian dalam musik gereja. Dalam bukunya Gereja yang Bernyanyi menyebutkan musik gereja merupakan ungkapan isi hati orang percaya (Kristen) yang diungkapkan dalam bunyi-bunyi yang bernada dan berirama secara harmonis, antara lain dalam bentuk lagu dan nyanyian. ${ }^{8}$ Dari pennyataan ini dapat dilihat bahwa musik serta nyanyian dalam gereja mengambil peranan penting dalam peribadahan, karena musik dan nyanyian itu sangat mempengaruhi hati setiap orang dalam penyembahan kepada Allah.

Masalah yang diangkat dalam penulisan ini adalah, selain adanya kelompok jemaat yang menerima penggunaan nyanyian himne dan nyanyian

${ }^{3}$ Mawene, Gereja yang Bernyanyi Menghidupkan Ibadah dengan Lagu (Yogkakarta: PBMR ANDI, 2004), 49.

${ }^{4}$ John Handol ML, Nyanyian Lucifer (Yogyakarta: Yayasan ANDI, 2002), 94.

${ }^{5}$ James F. White, Pengantar Ibadah Kristen (Jakarta: BPK Gunung Mulia, 2002), 106.

${ }^{6}$ E .H. Van OLST, Alkitab dan Liturgi ( BPK Gunung Mulia, 1998), 111.

${ }^{7}$ Jarot Wijanarko, Pujian dan Penyembahan (Jakarta: Suara Pemulihan, 2006), 66.

${ }^{8}$ Mawene, Gereja Yang Bernyanyi (Yogjakarta: ANDI Offset, 2004), 10. 
kontemporer dalam peribadahan dalam jemaat di gereja Gereja Kemah Injil Indonesia jemaat Talitakumi, ada juga kelompok jemaat yang belum menerima penggunaan nyanyian kontemporer, dan lebih menerima penggunaan nyanyian himne dalam beribadah, serta kelompok jemaat yang lebih menerima nyanyian kontemporer dalam peribadahan. Masalah ini dapat diketahui oleh penulis melalui keterlibatan penulis dalam pelayanan di gereja tersebut.

\section{Pokok Masalah}

Sesuai dengan penjelasan latar belakang di atas, maka pokok masalahnya adalah:

Pertama, kendala-kendala apa saja yang menyebabkan sehingga terdapat kelompok di Gereja Kemah Injil Indonesia Jemaat Talitakumi kurang menerima nyanyian kontenporer ataupun himne dalam ibadah?

Kedua, metode apa yang efektif untuk digunakan dalam memadukan nyanyian himne dan nyanyian kontenporer dalam pelaksanaan ibadah?

\section{Tujuan Penelitian}

Adapun tujuan yang ingin dicapai pada akhir penulisan skripsi ini ialah mengetahui bentuk perpaduan seperti apakah yang dipakai untuk memadukan nyanyian himne dan nyanyian rohani kontemporer dalam ibadah di Gereja Kemah Injil Indonesia Jemaaat Talitakumi Makassar

\section{Manfaat Penelitian}

Adapun manfaat dari penulisan skripsi ini yaitu:

Pertama, penulis berharap agar melalui skripsi ini pembaca dapat memahami dengan benar tentang nyanyian kontemporer dan nyanyian himne.

Kedua, melalui skripsi ini dapat membantu kelompok di Gereja Kemah Injil Indoonesia jemaat Talitakumi yang belum menerima nyanyian kontemporer agar dapat menerima nyanyian kontemporer sebagai pelengkap dalam pelaksanaan ibadah.

Ketiga, agar setiap jemaat dapat menegrti dan menyadari betapa pentingnya perpaduan antara nyanyian himne dan nyanyian kontemporer dalam ibadah sebagai pendukung yang membawa orang pada pengenalan akan Allah.

Keempat, agar jemaat dapat mengetahui manfaat dan pengaruh dari perpaduan nyanyian himne dan nyanyian kontemporer

Kelima, sebagai salah satu persyaratan untuk mencapai gelar sarjana Theologia di Sekolah Tinggi Jaffray Makassar. 


\section{Metode Penelitian}

Metode penelitian yang digunakan oleh penulis skripsi ini untuk memperoleh data bagi penulisan skripsi ini adalah metode kualitatif, dengan penelitian kepustakan atau library research, dan metode wawancara. ${ }^{9}$

\section{Batasan Penelitian}

Agar pembahasan dalam skripsi ini benar-benar terarah kepada suatu permasalahan yang dapat dipahami oleh para pembaca, maka penulis membatasi pembahasan skripsi ini pada hal-hal khusus yang berkaitan langsung dengan metode perpaduan nyanyian himne dan nyanyian rohani kontemporer dalam peribadahan hanya berfokus pada ruang lingkup Gereja Kemah Injil Jemaat Indonesi jemaat Talitakumi Makassar.

\section{Kepustakaan}

Handol ML, John. Nyanyian Lucifer. Yogyakarta: Yayasan ANDI, 2002.

Mawene. Gereja yang Bernyanyi Menghidupkan Ibadah dengan Lagu. Yogkakarta: PBMR ANDI, 2004.

Selvaraj, Sadhu Sundar. Seni Menyembah Menjadi Penyembah yang Dicari Tuhan. Jakarta: Nabiri Gabrie, 1996.

Siahaan, Rohani. "Memahami Nyanyian Jemaat Sebagai Sentral Musik Gereja Apa dan Bagaimana?" Jurnal Jaffray 10, no. 2 (2012). http://dx.doi.org/10.25278/ji71.v10i2.57

Siahaan, Rohani. "Memuji Dengan Nyanyian Dalam Ibadah Jemaat.” Jurnal Jaffray 5, no. 1 (2007). http://dx.doi.org/10.25278/jij1.v5i1.122

Siahaan, Rohani. " Analisis Pengaruh Nyanyian Jemaat Terhadap Kualitas Ibadah Gereja Protestan di Indonesia bagian Barat (GPIB) Jemaat Bukit Zaitun Makassar." Jurnal Jaffray 11, no. 2 (2013). http://dx.doi.org/10.25278/jij1.v11i2.82

${ }^{9}$ Tidak terdapat data statistika dalam penelitian ini sehingga penelitian ini termasuk penelitian kualitatif. Hengki Wijaya, Analisis Data Kualitatif: Ilmu Pendidikan Teologi (Makassar: Sekolah Tinggi Theologia Jaffray, 2018), 2. 
Sorge, Bob. Mengungkapkan Segi Pujian dan Penyembahan. Yogyakarta: ANDI 1991.

Van OLST E .H. Alkitab dan Liturgi. BPK Gunung Mulia, 1998.

White, James F. Pengantar Ibadah Kristen. Jakarta: BPK Gunung Mulia, 2002.

Wijanarko, Jarot. Pujian dan Penyembahan. Jakarta: Suara Pemulihan, 2006.

Wijaya, Hengki. Analisis Data Kualitatif: Ilmu Pendidikan Teologi. Makassar: Sekolah Tinggi Theologia Jaffray, 2018. 